\title{
LETTERS
}

\section{Gastroesophageal reflux disease, temporomandibular disorders and dysfunctional breathing}

In their study, Li and colleagues found that gastroesophageal reflux disease (GERD) was associated with temporomandibular disorders (TMDs), mediated to a certain extent by somatization, anxiety and poor sleep. ${ }^{1}$ However, the authors did not describe a contributory pathophysiological mechanism, hyperventilation, ${ }^{2}$ or assessment of breathing pattern and posture.

Relaxed diaphragmatic breathing appears to reduce the severity of GERD. ${ }^{3}$ During inspiration, the crural diaphragm provides an additional extrinsic sphincter independent of the lower esophageal sphincter. ${ }^{3}$ As assessed by $\mathrm{pH}$-metry, qualityof-life scores and proton pump inhibitor usage, relaxed diaphragmatic breathing reduces GERD severity. ${ }^{4}$ The teaching of relaxation skills and coping strategies is an effective, proven therapy for GERD. ${ }^{3,4}$

A consideration of breathing patterns potentially explains how biomechanical factors associated with psychosocial influences might contribute to pathophysiological changes in the temporomandibular joint. ${ }^{5}$ Patients with a dysfunctional breathing pattern typically have rounded shoulders and a forward head posture, ${ }^{6}$ which is implicated in TMDs. ${ }^{7} \mathrm{~A}$ forward head posture is believed to alter occlusion, lead to increased posterior tooth contact and increased temporomandibular joint compression: all anatomic changes emphasized in TMDs. ${ }^{6}$

The restoration of diaphragmatic breathing is an important musculoskeletal and psychological therapy used in helping patients with TMDs. ${ }^{6,8}$ Relaxed diaphragmatic breathing techniques also have an important role in managing anxiety ${ }^{9}$ and improving sleep quality. ${ }^{10}$
An assessment of a patient's posture and breathing pattern and, when necessary, instruction in relaxed diaphragmatic breathing may help people with these pathologies. Future research might also consider use of the Nijmegen questionnaire. ${ }^{2}$

\section{Jim R. Bartley MB ChB}

Otolaryngologist and pain medicine physician, Counties Manukau District Health Board, Auckland, New Zealand

- Cite as: CMAJ 2019 November 11;191: E1255. doi: 10.1503/cmaj.73545

\section{References}

1. Li Y, Fang M, Niu L, et al. Associations among gastroesophageal reflux disease, mental disorders, sleep and chronic temporomandibular disorder: a case-control study. CMAJ 2019;191:E909-15.

2. Vansteenkiste J, Rochette F, Demedts M. Diagnostic tests of hyperventilation syndrome. Eur Respir J 1991;4:393-9.

3. Casale M, Sabatino L, Moffa A, et al. Breathing training on lower esophageal sphincter as a complementary treatment of gastroesophageal reflux disease (GERD): a systematic review. Eur Rev Med Pharmacol Sci 2016;20:4547-52.

4. Eherer AJ, Netolitzky F, Högenauer C, et al. Positive effect of abdominal breathing exercise on gastroesophageal reflux disease: a randomized controlled study. Am J Gastroenterol 2012;107:372-8.

5. Bartley J. Breathing and temporomandibular joint disease. J Bodyw Mov Ther 2011;15:291-7.

6. Hruska RJJ. Influences of dysfunctional respiratory mechanics on orofacial pain. Dent Clin North Am 1997;41:211-27.

7. Rocha CP, Croci CS, Caria PH. Is there relationship between temporomandibular disorders and head and cervical posture? A systematic review. J Oral Rehabil 2013;40:875-81.

8. Sherman JJ, Turk DC. Nonpharmacologic approaches to the management of myofascial temporomandibular joint disorders. Curr Pain Headache Rep 2001;5:421-31.

9. Jerath R, Crawford MW, Barnes VA, et al. Selfregulation of breathing as a primary treatment for anxiety. Appl Psychophysiol Biofeedback 2015; 40:107-15.

10. Neuendorf R, Wahbeh $\mathrm{H}$, Chamine I, et al. The effects of mind-body interventions on sleep quality: a systematic review. Evid Based Complement Alternat Med 2015;2015:902708.

Competing interests: None declared. 